\title{
Novel platinum-palladium bimetallic nanoparticles synthesized by Dioscorea bulbifera: anticancer and antioxidant activities
}

This article was published in the following Dove Press journal:

International Journal of Nanomedicine

17 December 2015

Number of times this article has been viewed

\author{
Sougata Ghosh' \\ Rahul Nitnavare' \\ Ankush Dewle' \\ Geetanjali B Tomar' \\ Rohan Chippalkatti' \\ Piyush More' \\ Rohini Kitture ${ }^{2}$ \\ Sangeeta Kale ${ }^{2}$ \\ Jayesh Bellare ${ }^{3}$ \\ Balu A Chopade 4 \\ Institute of Bioinformatics and \\ Biotechnology, University of Pune, \\ ${ }^{2}$ Department of Applied Physics, \\ Defense Institute of Advanced \\ Technology, Pune, ${ }^{3}$ Department of \\ Chemical Engineering, Indian Institute \\ of Technology Bombay, Mumbai, \\ ${ }^{4}$ Department of Microbiology, \\ University of Pune, Pune, India
}

\begin{abstract}
Medicinal plants serve as rich sources of diverse bioactive phytochemicals that might even take part in bioreduction and stabilization of phytogenic nanoparticles with immense therapeutic properties. Herein, we report for the first time the rapid efficient synthesis of novel platinum-palladium bimetallic nanoparticles (Pt-PdNPs) along with individual platinum (PtNPs) and palladium (PdNPs) nanoparticles using a medicinal plant, Dioscorea bulbifera tuber extract (DBTE). High-resolution transmission electron microscopy revealed monodispersed PtNPs of size 2-5 nm, while PdNPs and Pt-PdNPs between 10 and $25 \mathrm{~nm}$. Energy dispersive spectroscopy analysis confirmed $30.88 \% \pm 1.73 \%$ elemental Pt and $68.96 \% \pm 1.48 \%$ elemental Pd in the bimetallic nanoparticles. Fourier transform infrared spectra indicated strong peaks at 3,373 $\mathrm{cm}^{-1}$, attributed to hydroxyl group of polyphenolic compounds in DBTE that might play a key role in bioreduction in addition to the sharp peaks at 2,937, 1,647, 1,518, and $1,024 \mathrm{~cm}^{-1}$, associated with $\mathrm{C}-\mathrm{H}$ stretching, $\mathrm{N}-\mathrm{H}$ bending in primary amines, $\mathrm{N}-\mathrm{O}$ stretching in nitro group, and $\mathrm{C}-\mathrm{C}$ stretch, respectively. Anticancer activity against HeLa cells showed that Pt-PdNPs exhibited more pronounced cell death of $74.25 \%$ compared to individual PtNPs (12.6\%) or PdNPs (33.15\%). Further, Pt-PdNPs showed an enhanced scavenging activity against 2,2-diphenyl-1-picrylhydrazyl, superoxide, nitric oxide, and hydroxyl radicals.
\end{abstract}

Keywords: Dioscorea bulbifera, platinum nanoparticles, palladium nanoparticles, platinumpalladium bimetallic nanoparticles, anticancer, antioxidant

\section{Introduction}

Nanoparticles of noble metals are gaining immense importance recently, owing to their noteworthy physicochemical properties unlike the bulk metal. ${ }^{1}$ At the same time search for safe and environmentally benign route toward synthesis of nanoparticles useful to human health has got prime attention. Nanoparticles are synthesized using diverse approaches like chemical, physical, and biological methods..$^{2-9}$ However, use of toxic chemicals for nanoparticles synthesis and stabilization lead to environmental hazards and limits their medicinal importance. Thus, biological synthesis of nanoparticles by plants, bacteria, and fungi are being investigated widely. However, there are only preliminary reports on biological synthesis of platinum nanoparticles (PtNPs) or palladium nanoparticles (PdNPs). PtNPs are used as catalysts for power generation in fuel cell. Further, they can reduce the toxic components of pollutants and play a key role in most of the important reactions for synthesis such as hydrogenation, oxidation, and hydration. ${ }^{10}$ Most recently, synthesis of monodispersed PtNPs is considered to be one of the important aspects due to its shape and size dependent activity. Pt nanocubes and nano-octahedra are recently reported to exhibit efficient catalytic activity for
Correspondence: Balu A Chopade Vice-Chancellor's Office, Dr Babasaheb Ambedkar Marathwada University, Jaisingpura, Aurangabad 431004, India Tel $+9 \mid 2025690643$

Fax+91 2025690087

Email vc@bamu.ac.in 
methanol and ethanol electro-oxidation, and also in hydrogen adsorption, desorption, ethylene hydrogenation, benzene hydrogenation, and $p$-nitrophenol hydrogenation, as well as for electrocatalytic applications. ${ }^{11-14} \mathrm{Pt}$ compound, cisplatin (cis-diaminedichloroplatinum) is a well known anticancer agent although it has high possibilities of treatment associated side effects. ${ }^{15}$ Similarly, another such noble metal, $\mathrm{Pd}$ is also well known for its catalytic properties in carbon-carbon and carbon-heteroatom coupling reactions. It is also used for synthesizing complex organic molecules. ${ }^{16}$ PdNPs are synthesized by various approaches like electrochemical deposition, sonochemical decomposition, and reduction of $\mathrm{Pd}$ salts by a variety of reducing agents that mostly involve toxic and hazardous chemicals. ${ }^{17}$ There are only preliminary reports on PdNPs to induce disturbances in cell cycle arrest. ${ }^{18}$ Till date the anticancer activity of bimetallic platinum-palladium nanoparticles (Pt-PdNPs) has never been tested.

In view of this background, there is a need to develop environmental friendly route to synthesize Pt-PdNPs with enhanced medicinal properties without involvement of toxic chemicals. Unfortunately, there are no reports on synthesis of bimetallic Pt-PdNPs by medicinal plants like Dioscorea bulbifera. Medicinal plants have always been preferred over other biological methods owing to their biocompatibility, rapid and efficient synthesis mechanism. ${ }^{19-23}$ D. bulbifera, has immense therapeutic significance in traditional complementary and alternative medicine for treatment of diabetes, sore throat, ulcers, tumor, cancer, and oxidative stress related degenerative disease. ${ }^{24-27}$ Similarly, it has been extensively used for synthesis of metal nanoparticles like gold, silver, and gold core silver shell ( $\left.\mathrm{Au}_{\text {core }} \mathrm{Ag}_{\text {shell }} \mathrm{NPs}\right)$ bimetallic nanoparticles. ${ }^{28-30}$

Hereby, as a part of our growing interest in nanobiotechnology, herein we report for the first time, the synthesis of Pt-PdNPs by a medicinal plant, D. bulbifera. The bioreduced nanoparticles were further investigated for anticancer and antioxidant activities.

\section{Materials and methods}

\section{Plant material and preparation of extract}

D. bulbifera tuber extract (DBTE) was prepared as per our earlier report. ${ }^{30}$ In short, the tubers were collected from Western Ghats of Maharashtra, India, which were rinsed thoroughly under running tap water followed by chopping into thin slices and shade drying for 2 days at room temperature. After complete drying, the slices were pounded in an electric blender. Five gram of finely ground tuber powder was taken in a $300 \mathrm{~mL}$ Erlenmeyer flask with $100 \mathrm{~mL}$ of sterile distilled water and boiled for 5 minutes before final decantation and filtration through Whatman No 1 filter paper. The filtrate was collected and stored at $4^{\circ} \mathrm{C}$ for further use.

\section{Synthesis of PtNPs, PdNPs, and Pt-PdNPs and UV-visble spectroscopy}

$\mathrm{PtCl}_{6}{ }^{2-}$ ions were reduced by addition of $5 \mathrm{~mL}$ of DBTE to $95 \mathrm{~mL}$ of $10^{-3} \mathrm{M}$ aqueous $\mathrm{H}_{2} \mathrm{PtCl}_{6} \cdot 6 \mathrm{H}_{2} \mathrm{O}$ solution. Similarly, PdNPs were synthesized by addition of $5 \mathrm{~mL}$ of DBTE to $95 \mathrm{~mL}$ of $10^{-3} \mathrm{M}$ aqueous $\mathrm{PdCl}_{2}$. Synthesis of PtNPs and PdNPs were achieved by carrying out the reaction at $100^{\circ} \mathrm{C}$ for 5 hours, which was monitored by UV-visble spectroscopy on a spectrophotometer (SpectraMax M5, Molecular Devices Corporation, Sunnyvale, CA, USA) operated at a resolution of $1 \mathrm{~nm}$. In case of synthesis of Pt-PdNPs, $5 \mathrm{~mL}$ of DBTE was added to $95 \mathrm{~mL}$ of aqueous solution containing $10^{-3} \mathrm{M}$ of both $\mathrm{H}_{2} \mathrm{PtCl}_{6} \cdot 6 \mathrm{H}_{2} \mathrm{O}$ and $\mathrm{PdCl}_{2}$. The conditions for the synthesis were kept similar as that of the individual synthesis of PtNPs and PdNPs. In order to set up control experiments with variable elemental ratio in bimetallic particles, synthesis was tried by varying the $\mathrm{Pt}$ and $\mathrm{Pd}$ salt concentration in ratio $1: 2$, as well as 2:1. Chemical synthesis of PtNPs, PdNPs, and Pt-PdNPs was carried out as per an earlier report by Shafii et al, ${ }^{31}$ with some modifications. ${ }^{31}$ In short, $10^{-3} \mathrm{M} \mathrm{PdCl}_{2}$ were converted to $\mathrm{H}_{2} \mathrm{PdCl}_{4} \cdot \mathrm{nH}_{2} \mathrm{O}$ by addition of $100 \mu \mathrm{L}$ of concentrated $\mathrm{HCl}$, then $10^{-3} \mathrm{M} \mathrm{H}_{2} \mathrm{PtCl}_{6} \cdot 6 \mathrm{H}_{2} \mathrm{O}$ followed by addition of $1.11 \mathrm{~g}$ polyvinylpyrrolidone (PVP) to the mixture of methanol $(130 \mathrm{~mL})$ and distilled water $(150 \mathrm{~mL})$ acting as solvent. Mixing of the solution was carried out in $500 \mathrm{~mL}$ three-neck round bottomed flask with drop wise addition of $20 \mathrm{~mL}$ of $0.1 \mathrm{M} \mathrm{NaOH}$ in methanol under vigorous stirring. Bimetallic Pt-PdNPs were synthesized by conventional refluxing of the above mixture for 3 hours. Similar process was followed for individual synthesis of PtNPs and PdNPs. The resulting final colloidal nanoparticles solution with a dark brown color was stored in dark bottles at $4^{\circ} \mathrm{C}$ for further use. Control experiments with DBTE, chemically synthesized nanoparticles only as well as with DBTE and Pt-PdNPs with varied elemental ratio were run for all biological experiments.

\section{HRTEM and EDS}

Surface morphology and particle size of bioreduced PtNPs, PdNPs, and Pt-PdNPs were determined using transmission electron microscope (Tecnai 12 cryo TEM, FEI, Eindhoven, the Netherlands). The morphology and size of bioreduced nanoparticles were characterized by JEOL-JEM-2100 (JEOL, Akishima, Tokyo, Japan) high-resolution transmission electron microscope (HRTEM). Energy dispersive spectra 
recorded in the energy dispersive spectroscopy (EDS) equipped in JEOL JSM 6360A analytical scanning electron microscope at an energy range $0-20 \mathrm{keV}$ confirmed the synthesis of PtNPs, PdNPs, and Pt-PdNPs using DBTE. The diffraction data for the dry powder were recorded on a Bruker X-ray diffractometer using a $\mathrm{Cu} \mathrm{K} \alpha(1.54 \AA)$ source. Phase formation was confirmed from characteristic peaks such as (111), (200), and (220).

\section{FTIR spectroscopy}

PtNPs, PdNPs, and Pt-PdNPs synthesized after 5 hours of reaction were centrifuged at $10,000 \mathrm{rpm}$ for 15 minutes at room temperature, following which the pellet was redispersed in sterile distilled water to remove any plant materials. The process of centrifugation and redispersion in sterile distilled water was repeated thrice to ensure better separation of free entities from the nanoparticles. The purified pellet was then dried and subjected to Fourier transform infrared (FTIR; IRAffinity-1, Shimadzu Corp, Tokyo, Japan) spectroscopy measurement using the potassium bromide pellet technique in the diffused reflection mode at a resolution of $4 \mathrm{~cm}^{-1}$. Nanoparticle powders were mixed with potassium bromide and subjected to IR source $500-4,000 \mathrm{~cm}^{-1}$. Similar process was used for the FTIR study of DBTE before and after bioreduction.

\section{Cell toxicity assay}

Antiproliferative activities of PtNPs, PdNPs, and Pt-PdNPs were evaluated against HeLa cells employing 3-(4,5dimethylthiazol-2-yl)-2,5-diphenyltetrazolium bromide (MTT) assay as per our earlier report. ${ }^{19}$ In short, HeLa cell line (human epithelial cervical cancer) was obtained from National Centre for Cell Science, Pune, India and cultured in Dulbecco's Modified Eagle's Medium, supplemented with $10 \%$ fetal bovine serum, streptomycin $\left(100 \mathrm{~g} \mathrm{~mL}^{-1}\right)$ and penicillin $\left(100 \mathrm{U} \mathrm{mL}^{-1}\right)$ and were maintained in a humidified atmosphere at $37^{\circ} \mathrm{C}$ and $5 \% \mathrm{CO}_{2}$. Cells $\left(4 \times 10^{4}\right)$ were seeded per well in a 96-well plate. The nanoparticles were added to the cells at a concentration of $10 \mu \mathrm{g} \mathrm{mL}^{-1}$ after 24 hours of seeding. After 48 hours, media was removed and the cells were washed with phosphate-buffered saline. MTT $\left(0.5 \mathrm{mg} \mathrm{mL}^{-1}\right)$ was added to the wells and incubated for 2 hours. The formazan crystals were dissolved using acidified isopropanol and the absorbance was measured at $570 \mathrm{~nm}$ on a microplate reader (SpectraMax M5, Molecular Devices Corporation). Control experiments were also run with DBTE, chemically synthesized nanoparticles only as well as with DBTE and Pt-PdNPs with varied elemental ratio. The statistical analysis was done by using one-way analysis of variance.

\section{Flow cytometric analysis}

Confirmation of apoptosis as most predominant mechanism behind the antiproliferative activity of the bioreduced nanoparticles was carried out by a flow cytometric analysis of cells treated with respective nanoparticles. Cells $\left(5 \times 10^{5}\right)$ were seeded in a T-25 flask and incubated for 24 hours followed by treatment with PtNPs, PdNPs, and Pt-PdNPs at a concentration of $10 \mu \mathrm{g} \mathrm{mL}^{-1}$. After 48 hours of incubation the cells were harvested and stained with Annexin-V (AV)-fluorescein isothiocyanate (FITC) and propidium iodide (PI) at a dilution of $1: 20$, for $10-15$ minutes at $4^{\circ} \mathrm{C}$. These were then acquired in BD FACSCalibur and analyzed using Cell Quest Pro software.

\section{Confocal microscopy}

HeLa cells were seeded on to glass cover slips at a density of $5 \times 10^{4}$ cells. After 24 hours of incubation the cells were treated as per the above protocol. Treated cells were stained with AV-FITC and PI, both at a dilution of 1:20 for $15 \mathrm{~min}-$ utes at $4{ }^{\circ} \mathrm{C}$ and were fixed in $4 \%$ paraformaldehyde followed by observation under LSM 780 confocal laser scanning microscope, Carl Zeiss (magnification $\times 40$ ).

\section{DPPH radical scavenging assay}

Twenty microliters of each of PtNPs, PdNPs, and Pt-PdNPs were mixed with $80 \mu \mathrm{L}$ of methanolic solution of 2,2diphenyl-1-picrylhydrazyl (DPPH; $100 \mu \mathrm{M}$ ) and incubated in darkness for 30 minutes in a 96-well plate. ${ }^{32,33}$ Absorbance was recorded at $517 \mathrm{~nm}$ in a 96-well plate reader (SpectraMax M5, Molecular Devices Corporation) and scavenging activity was found out by the following formula:

$\%$ scavenging $=\mathrm{A} 517_{\text {Control }}-\mathrm{A} 517_{\text {Test }} / \mathrm{A} 517_{\text {Control }} \times 100$

\section{Superoxide anion scavenging assay}

Nitroblue tetrazolium reduction in a non-enzymatic phenazine methosulfate-nicotinamide adenine dinucleotide (PMS-NADH) system through reaction of PMS, NADH, and oxygen was used to evaluate superoxide anion scavenging assay. Three hundred microliters of each of PtNPs, PdNPs, and Pt-PdNPs was added in $3 \mathrm{~mL}$ of Tris-HCl buffer (100 mM, pH 7.4) containing $750 \mu \mathrm{L}$ of nitroblue tetrazolium $(300 \mu \mathrm{M})$ solution and $750 \mu \mathrm{L}$ of NADH $(936 \mu \mathrm{M})$ solution. Seven hundred and fifty microliters of PMS $(120 \mu \mathrm{M})$ was added to the mixture and incubated for 5 minutes at room 
temperature, followed by recording of absorbance at $560 \mathrm{~nm}$. The following formula was used to calculate superoxide anion scavenging activity:

$\%$ scavenging $=\mathrm{A} 560_{\text {Control }}-\mathrm{A} 560_{\text {Test }} / \mathrm{A} 560_{\text {Control }} \times 100$

\section{Nitric oxide scavenging assay}

Five hundred microliters of each PtNPs, PdNPs, and Pt-PdNPs was added to a mixture of $2 \mathrm{~mL}$ of $10 \mathrm{mM}$ sodium nitroprusside in $500 \mu \mathrm{L}$ phosphate buffer saline ( $\mathrm{pH} 7.4)$ followed by incubation at $25^{\circ} \mathrm{C}$ for 2.5 hours. Next, $500 \mu \mathrm{L}$ from above reaction mixture was added into $1 \mathrm{~mL}$ sulphanilic acid reagent (33\% in 20\% glacial acetic acid) and incubated at room temperature for 5 minutes. Eventually, $1 \mathrm{~mL}$ naphthylethylenediamine dihydrochloride $(0.1 \% \mathrm{w} / \mathrm{v})$ was added and incubated for 0.5 hour at room temperature. Absorbance was recorded at $540 \mathrm{~nm}$ and the scavenging activity was calculated using the following equation:

$\%$ scavenging $=\mathrm{A} 540_{\text {Control }}-\mathrm{A} 540_{\text {Test }} / \mathrm{A} 540_{\text {Control }} \times 100$

\section{Hydroxyl radical scavenging assay}

Hydroxyl radical scavenging activity was estimated according to our earlier report. ${ }^{24}$ In short, $100 \mu \mathrm{L}$ of PtNPs, PdNPs, and $\mathrm{Pt}-\mathrm{PdNPs}$ were added separately to $400 \mu \mathrm{L}$ of phosphate buffer, followed by addition of $100 \mu \mathrm{L}$ of ethylenediaminetetraacetic acid $(1.04 \mathrm{mM}), 100 \mu \mathrm{L}$ of $\mathrm{FeCl}_{3}(1.0 \mathrm{mM})$, and $100 \mu \mathrm{L}$ of 2-deoxyribose $(60 \mathrm{mM})$. Initiation of reaction was achieved by addition of $100 \mu \mathrm{L}$ of ascorbic acid $(2 \mathrm{mM})$ and $100 \mu \mathrm{L}$ of $\mathrm{H}_{2} \mathrm{O}_{2}(10 \mathrm{mM})$ into the mixture keeping in water bath at $37^{\circ} \mathrm{C}$. One microliter of cold thiobarbituric acid $\left(10 \mathrm{~g} \mathrm{~L}^{-1}\right)$ was added after 1 hour followed by $1 \mathrm{~mL}$ of $\mathrm{HCl}(25 \%)$ and boiled for 15 minutes at $100^{\circ} \mathrm{C}$. Absorbance was recorded at $532 \mathrm{~nm}$. The following formula was used to evaluate hydroxyl radical scavenging capacity:

$\%$ scavenging $=\mathrm{A} 532_{\text {Control }}-\mathrm{A} 532_{\text {Test }} / \mathrm{A} 532_{\text {Control }} \times 100$

\section{Results}

\section{UV-visible spectroscopy}

Bioreduction of Pt ions to PtNPs on exposure to DBTE was monitored by tracking the color change and with UV-visble spectroscopy. Facilitation of the bioconversion at an elevated temperature of $100^{\circ} \mathrm{C}$ was indicated by gradual color change of the light yellow Pt (IV) solution initially to brown representing Pt (II) and finally from brown to black marking the formation of $\mathrm{Pt}(0)$. Entire reaction was found to be completed in 5 hours. The UV-visible spectra indicates a lower rate of PtNPs synthesis, which might be probably due to difficulty in initially forming Pt nuclei, indicating the requirement of longer duration and higher temperature for complete synthesis of PtNPs. Similarly, addition of DBTE into Pd ion solution showed a gradual color change from transparent orange to dark brown over the time span of 5 hours. The observed emergence of brown color, attributed due to the excitations of surface plasmon vibrations, indicates the synthesis of PdNPs, which was further confirmed by UV-visible analysis (Figure 1). The observed absence of peak at $420 \mathrm{~nm}$ specific to $\mathrm{Pd}^{2+}$ ions in reaction mixture indicated the complete reduction of the $\mathrm{Pd}^{2+}$ ions to PdNPs after 5 hours at $100^{\circ} \mathrm{C}$. Bimetallic Pt-PdNPs showed an intense dark brown color on completion of the bioreduction after 5 hours. The absorbance was found to be higher as compared to both PtNPs and PdNPs alone. The as synthesized nanoparticles were used for all further characterization, while the obtained nanoparticles were collected by centrifugation and washed by repetition of alternate redispersion in distilled water and centrifugation for further biological studies.

\section{HRTEM, EDS, and XRD analysis}

Morphologies of the nanoparticles synthesized during bioreduction were confirmed by employing HRTEM analysis. PtNPs exhibited uniformly distributed spherical nanostructures between 2 and $5 \mathrm{~nm}$ (Figure 2A). The particles were not seen to be agglomerated and were well stabilized in the matrix of biomaterial. In case of the PdNPs, a mixture of spherical and blunt ended cubes was observed ranging from 10 to $20 \mathrm{~nm}$ (Figure 2B). It is important to note that the PdNPs were also found to be discrete and well in isolation. Pt-PdNPs were found in irregular shape ranging between 20 and $25 \mathrm{~nm}$ (Figure 2C). TEM images of the chemically synthesized

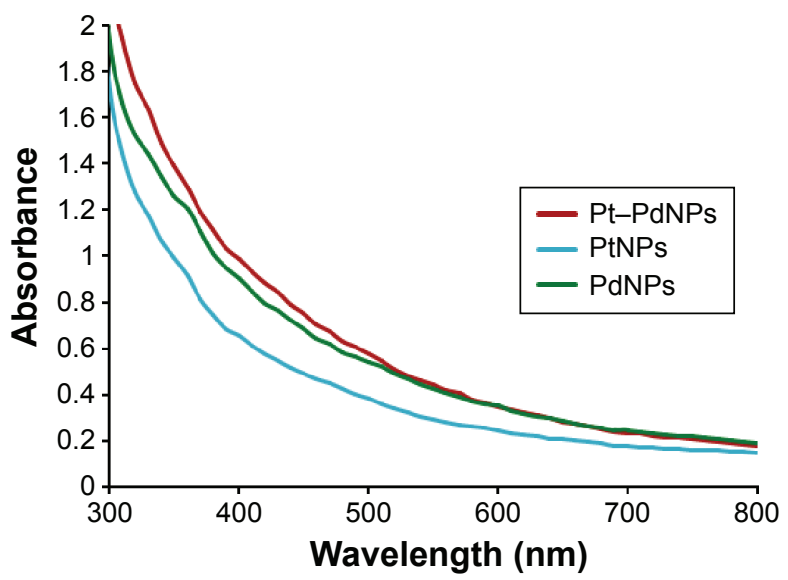

Figure I UV-visible spectra of PtNPs, PdNPs, and Pt-PdNPs synthesized by DBTE. Abbreviations: DBTE, Dioscorea bulbifera tuber extract; PdNPs, palladium nanoparticles; PtNPs, platinum nanoparticles; Pt-PdNPs, platinum-palladium bimetallic nanoparticles. 

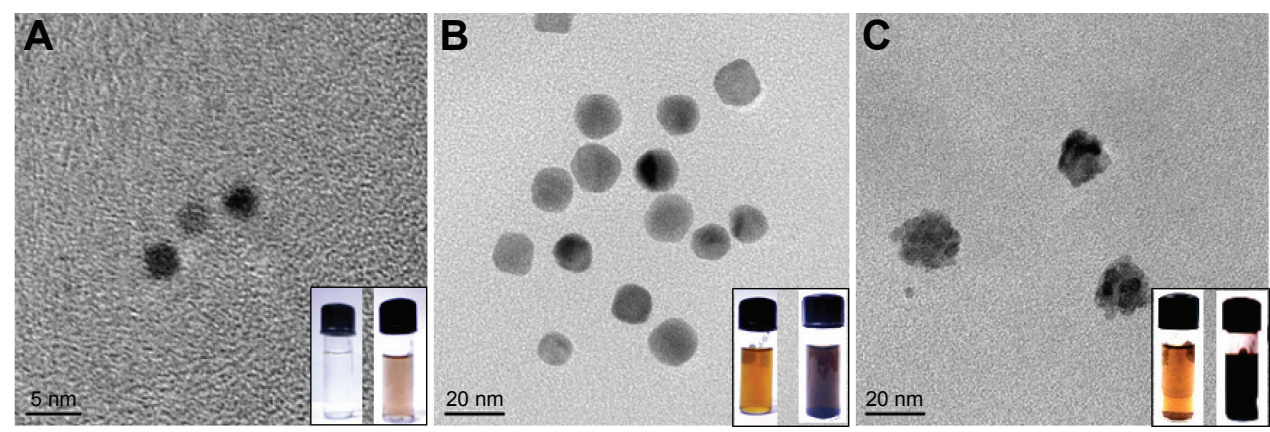

Figure 2 High-resolution transmission electron micrographs of nanoparticles synthesized by DBTE.

Notes: (A) PtNPs with inset showing color change on bioreduction of Pt salt to PtNPs; (B) PdNPs with inset showing color change on bioreduction of Pd salt to PdNPs; (C) Pt-PdNPs with inset showing color change on bioreduction of Pt and Pd salt solution to Pt-PdNPs.

Abbreviations: DBTE, Dioscorea bulbifera tuber extract; PdNPs, palladium nanoparticles; PtNPs, platinum nanoparticles; Pt-PdNPs, platinum-palladium bimetallic nanoparticles.

nanoparticles are given in Figure S1. EDS analysis confirmed the presence of elemental Pt up to $99.65 \% \pm 3.14 \%$ in PtNPs indicating the purity of the bioreduced nanoparticles. Similarly, elemental Pd content up to $99.18 \% \pm 2.84 \%$ in PdNPs supported its purity and establishes the efficiency of the DBTE to form pure metallic nanoparticles. Further, EDS analysis clearly indicated that bimetallic nanoparticles were comprised of $30.88 \% \pm 1.73 \%$ elemental Pt and $68.96 \% \pm 1.48 \%$ elemental Pd (Figure 3 ). EDS analysis data for chemically synthesized and other control nanoparticles are included in Figure S2. Figure S3 shows X-ray diffraction (XRD) pattern of the PtNPs, PdNPs, and Pt-PdNPs synthesized by DBTE. The (111), (200), and (220) planes in PtNPs at the respective $2 \theta$ positions of $39.7^{\circ}, 46.2^{\circ}$, and $67.4^{\circ}$ confirm the face centered cubic phase as per the JCPDS card no 04-0802. Pt-PdNPs also showed the presence of (111), (200), and (220) peaks, with their respective diffraction positions shifted slightly toward higher $2 \theta$ values. The noise in the XRD data of the PdNPs suppressed their characteristic peaks, but the EDS data supports the presence of the PdNPs.

\section{FTIR analysis}

FTIR spectrum of DBTE showed strong peaks at 3,373 $\mathrm{cm}^{-1}$, which is attributed to hydroxyl group in polyphenolic compounds (Figure 4). Additionally, the other peaks in the spectrum of DBTE corresponding to the characteristic groups were found to be in agreement to our previous report. ${ }^{29}$ Sharp peaks at 2,937, 1,647, 1,518, and 1,024 $\mathrm{cm}^{-1}$, associated with $\mathrm{C}-\mathrm{H}$ stretching, $\mathrm{N}-\mathrm{H}$ bending in primary amines, $\mathrm{N}-\mathrm{O}$ stretching in nitro group, and $\mathrm{C}-\mathrm{C}$ stretch, respectively, were also observed in the DBTE. The presences of almost all the characteristic peaks of DBTE in the bioreduced nanoparticles indicated the stabilization of nanoparticles by DBTE may be due to coating. As seen in the other spectra, the peak intensity is reduced in the nanoparticles indicating relatively lesser concentration of DBTE taking part in the stabilization process. The peak at $1,415 \mathrm{~cm}^{-1}$, attributed to carboxylate group was found to diminish in the nanoparticles, indicating the possible conjugation of the nanoparticles with the extract through carboxylate group. Overall, it is supported herewith that DBTE plays a key role in reducing the metal ions to their corresponding metallic nanoparticles and further, through conjugation, making them stable in the medium.

\section{Cell viability}

MTT assay demonstrated cytotoxic effect of PtNPs (12.6\%), PdNPs (33.15\%), and Pt-PdNPs (74.25\%), with Pt-PdNPs to be the most toxic out of all the three nanoparticles, at a concentration of $10 \mu \mathrm{g} \mathrm{mL}^{-1}$ (Figure 5). An enhanced cytotoxic effect of Pt-PdNPs could be attributed to a synergistic effect of both the components. Chemically synthesized nanoparticles were found to be comparatively less potent, the data for which along with other control nanoparticles are included in Figure S4.

\section{Flow cytometric analysis}

Immunofluorescence analysis of the cells treated with nanoparticles indicated apoptosis of treated cells. Percentage of dual positive cells $\left(\mathrm{AV}-\mathrm{FITC}^{+} \mathrm{PI}^{+}\right.$) was observed to be higher in the groups treated with $\mathrm{Pt}-\mathrm{PdNPs}(20.60 \%)$ represented in the upper right quadrant of Figure $6 \mathrm{C}$ as compared to treatment groups of PtNPs and PdNPs alone as evident in similar quadrants of Figure 6A and B, respectively. The dual positivity indicated the cells in late apoptosis. Moreover, the total number of cells undergoing cell death was much higher in Pt-PdNPs as compared to PtNPs or PdNPs alone, indicating a higher anticancer activity of Pt-PdNPs (Figure 6). The total number of cells in all of the three 

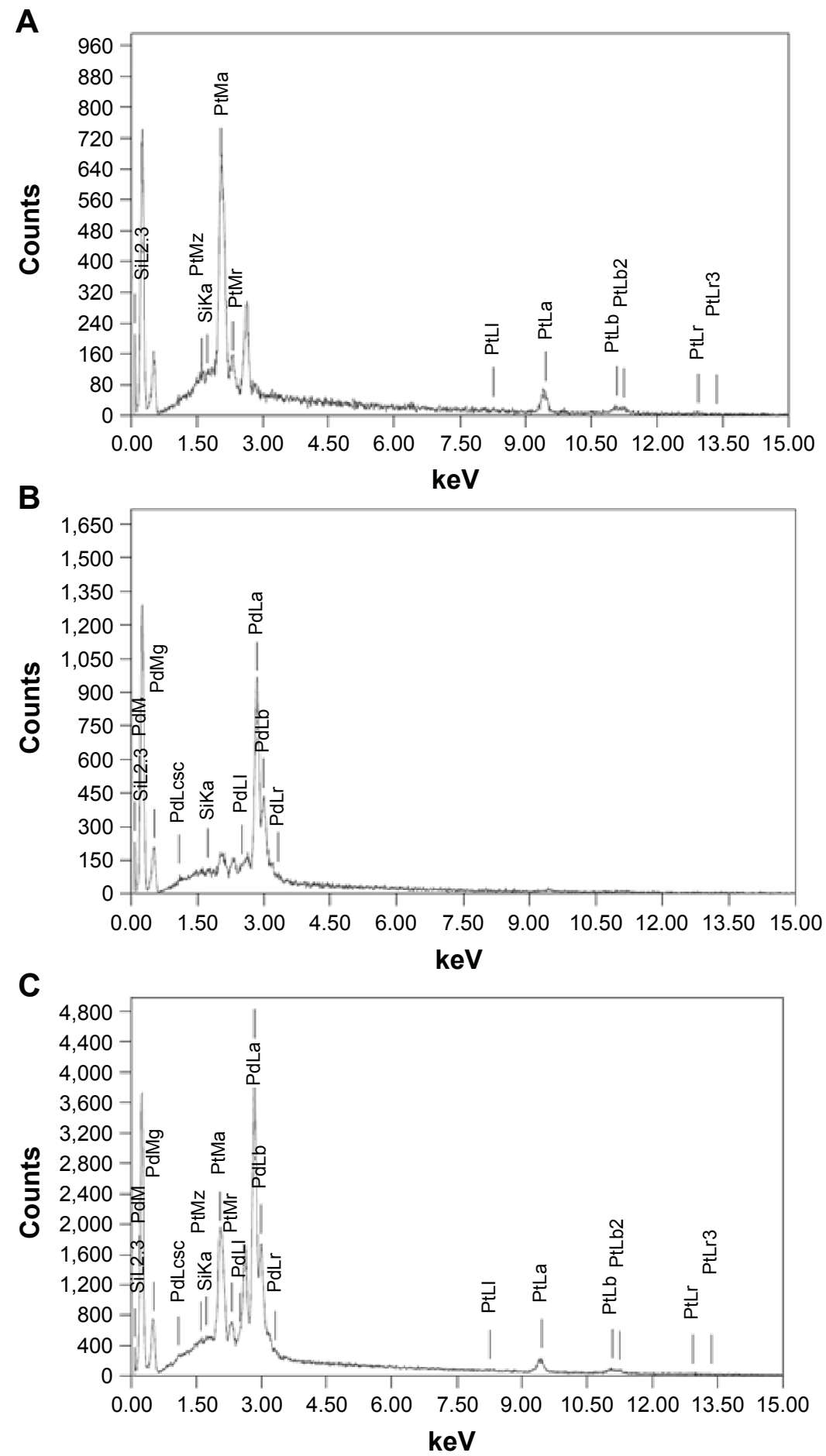

Figure 3 Representative spot EDS profile confirming the presence of respective metals in the nanoparticles synthesized by DBTE.

Notes: (A) PtNPs showing presence of elemental platinum; (B) PdNPs showing presence of elemental palladium; (C) Pt-PdNPs showing presence of elemental both platinum and palladium.

Abbreviations: DBTE, Dioscorea bulbifera tuber extract; EDS, energy dispersive spectroscopy; PdNPs, palladium nanoparticles; PtNPs, platinum nanoparticles; Pt-PdNPs, platinum-palladium bimetallic nanoparticles.

quadrants (indicating cells in early as well as late apoptosis) was much higher in Figure $6 \mathrm{C}$ representing treatment with Pt-PdNPs as compared to individual PtNPs or PdNPs.

Immunofluorescence imaging of the cells treated with nanoparticles supported the quantitative analysis done by flow cytometry. It was observed that the number of apoptotic cells after PtNPs treatment (Figure 7) was less, whereas the cells treated with PdNPs were necrotic. Treatment with Pt-PdNPs caused cell death due to apoptosis, shown by large number of dual positive cells. 


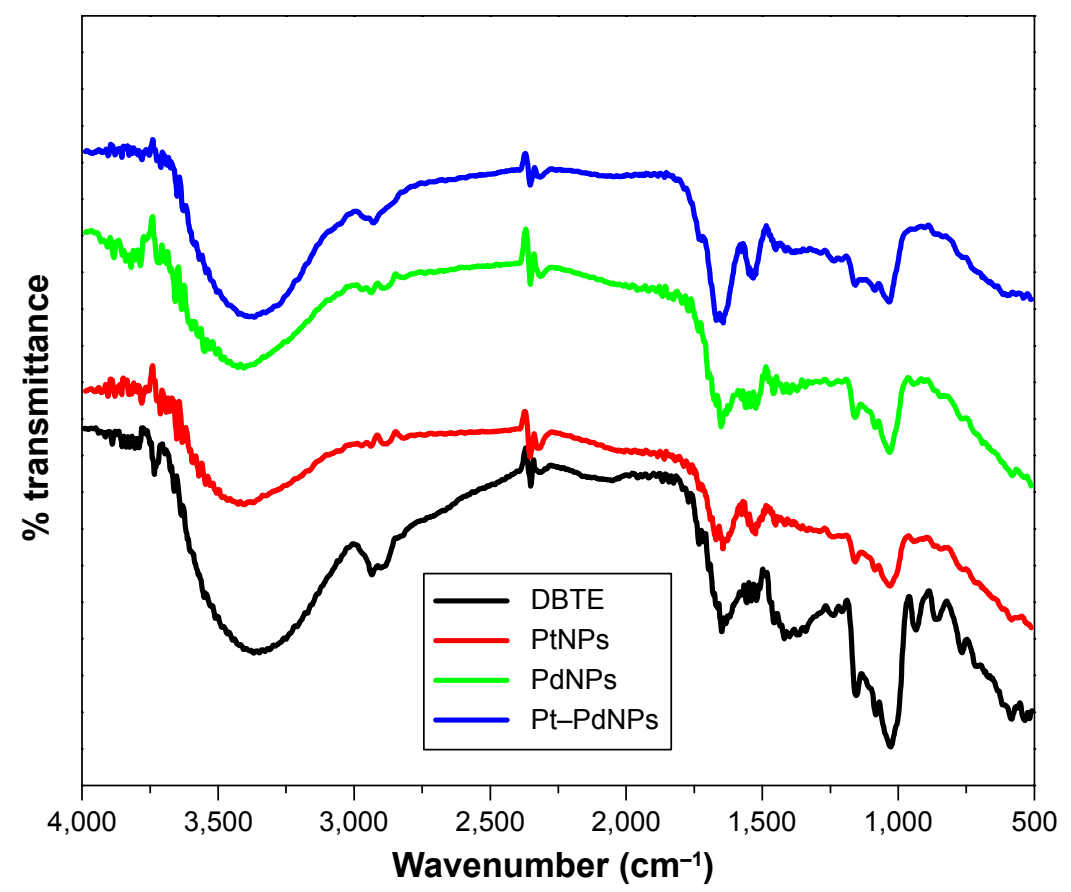

Figure 4 Fourier transform infrared absorption spectra of dried Dioscorea bulbifera tuber extract (DBTE) before bioreduction and after complete bioreduction of PtNPs, PdNPs, and Pt-PdNPs.

Abbreviations: PdNPs, palladium nanoparticles; PtNPs, platinum nanoparticles; Pt-PdNPs, platinum-palladium bimetallic nanoparticles.

\section{Antioxidant activity}

Antioxidant studies showed that PtNPs could scavenge DPPH radical up to $30.16 \% \pm 2.86 \%$, while PdNPs exhibited an activity up to $28.97 \% \pm 4.87 \%$ (Figure 8 ). However, Pt-PdNPs showed a superior activity of $38.49 \% \pm 4.67 \%$ as compared to individual PtNPs and PdNPs. Similarly, a synergistic enhancement of scavenging activity against superoxide radical was also observed for Pt-PdNPs $(56.71 \% \pm 0.4 \%)$ as compared with only PtNPs $(31.87 \% \pm 0.29 \%)$ or PdNPs $(27.1 \% \pm 0.69 \%)$. In case of nitric oxide scavenging activity

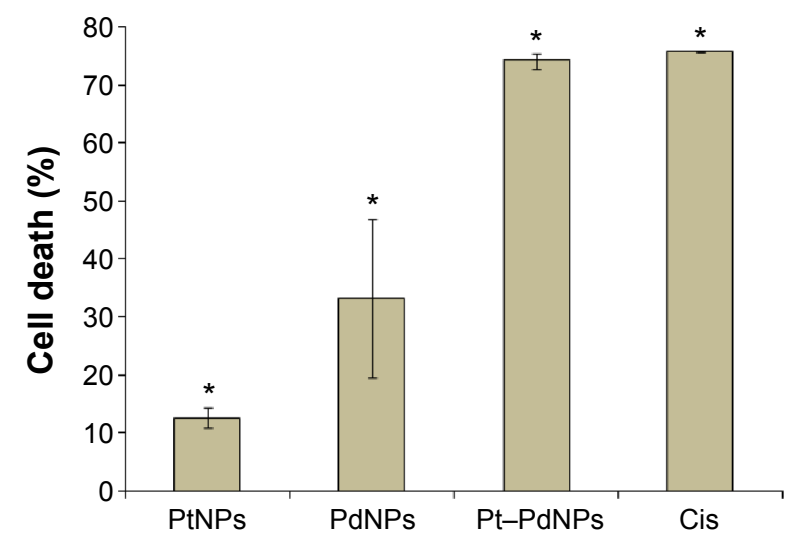

Figure 5 Antiproliferative activity of PtNPs, PdNPs, and Pt-PdNPs against HeLa cells. The data are expressed as a percentage of the control MTT reduction (always taken as $100 \%)$ and represent the average \pm SEM $(n=3)$; *indicates $P=0.05$.

Abbreviations: MTT, 3-(4,5-dimethylthiazol-2-yl)-2,5-diphenyltetrazolium bromide; PdNPs, palladium nanoparticles; PtNPs, platinum nanoparticles; Pt-PdNPs, platinum palladium bimetallic nanoparticles; SEM, standard error of the mean.
Pt-PdNPs showed a significantly superior activity of $47.17 \% \pm 1.59 \%$, while PtNPs and PdNPs individually showed a reduced activity of $11.11 \% \pm 1.35 \%$ and $10.53 \% \pm 2.54 \%$, respectively. A similar trend was observed in case of hydroxyl radical scavenging where activity of Pt-PdNPs was found to be $24.48 \% \pm 0.13 \%$, which was higher compared to either of PtNPs $(22.65 \% \pm 0.17 \%)$ or of PdNPs $(7.32 \% \pm 0.08 \%)$. Chemically synthesized nanoparticles showed comparatively reduced free radical scavenging activity, the data for which along with other control nanoparticles are included in Figure S5.

\section{Discussion}

Complex and unique phytochemistry of D. bulbifera is comprised of a wide family of bioactive natural components with potent pharmacological significance. These phytochemicals include saponins, reducing sugars, ascorbic acid, citric acid, phenolics, and flavonoids, which play a critical role in rapid synthesis and shape evolution of exotic metal nanoparticles. Hence, herein we achieved a rapid and efficient synthesis of PtNPs, PdNPs, and Pt-PdNPs within 5 hours at $100^{\circ} \mathrm{C}$. Conversion of yellow color of the solution to black marked the completion of the synthesis of PtNPs. Our results are in close agreement with the recent report on synthesis of PtNPs by Ocimum sanctum leaf extract, where it was found that the rate of synthesis of PtNPs increased from $20 \%$ at $60^{\circ} \mathrm{C}$ to $100 \%$ at $95^{\circ} \mathrm{C} .{ }^{34}$ Rate of synthesis of PtNPs was observed 

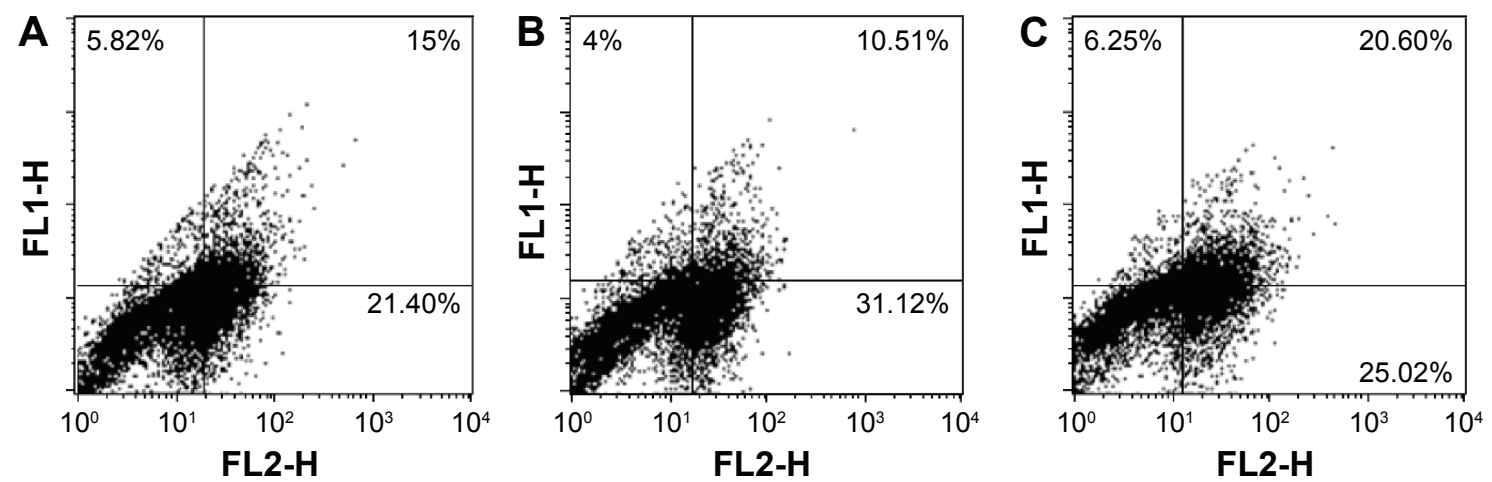

Figure 6 Flow cytometric analysis of phosphatidylserine externalization (annexin $\vee$ binding) and cell membrane integrity (PI staining) for HeLa cells treated with PtNPs, PdNPs, and Pt-PdNPs for 48 hours.

Notes: The dual parametric dot plots combining annexin $\mathrm{V}-\mathrm{FITC}$ and $\mathrm{PI}$ fluorescence show the viable cell population (lower left quadrant, annexin $\mathrm{V}^{-} \mathrm{PI}^{-}$), the early apoptotic cells (lower right quadrant, annexin $\mathrm{V}^{+} \mathrm{Pl}^{-}$), and the late apoptotic cells (upper right quadrant, annexin $\mathrm{V}^{+} \mathrm{PI}^{+}$). $(\mathbf{A}) \mathrm{Treatment}$ with $\mathrm{PtNPs}$; $(\mathbf{B})$ treatment with $\mathrm{PdNPs}$; (C) treatment with Pt-PdNPs.

Abbreviations: PdNPs, palladium nanoparticles; PI, propidium iodide; PtNPs, platinum nanoparticles; Pt-PdNPs, platinum-palladium bimetallic nanoparticles; FITC, fluorescein isothiocyanate.

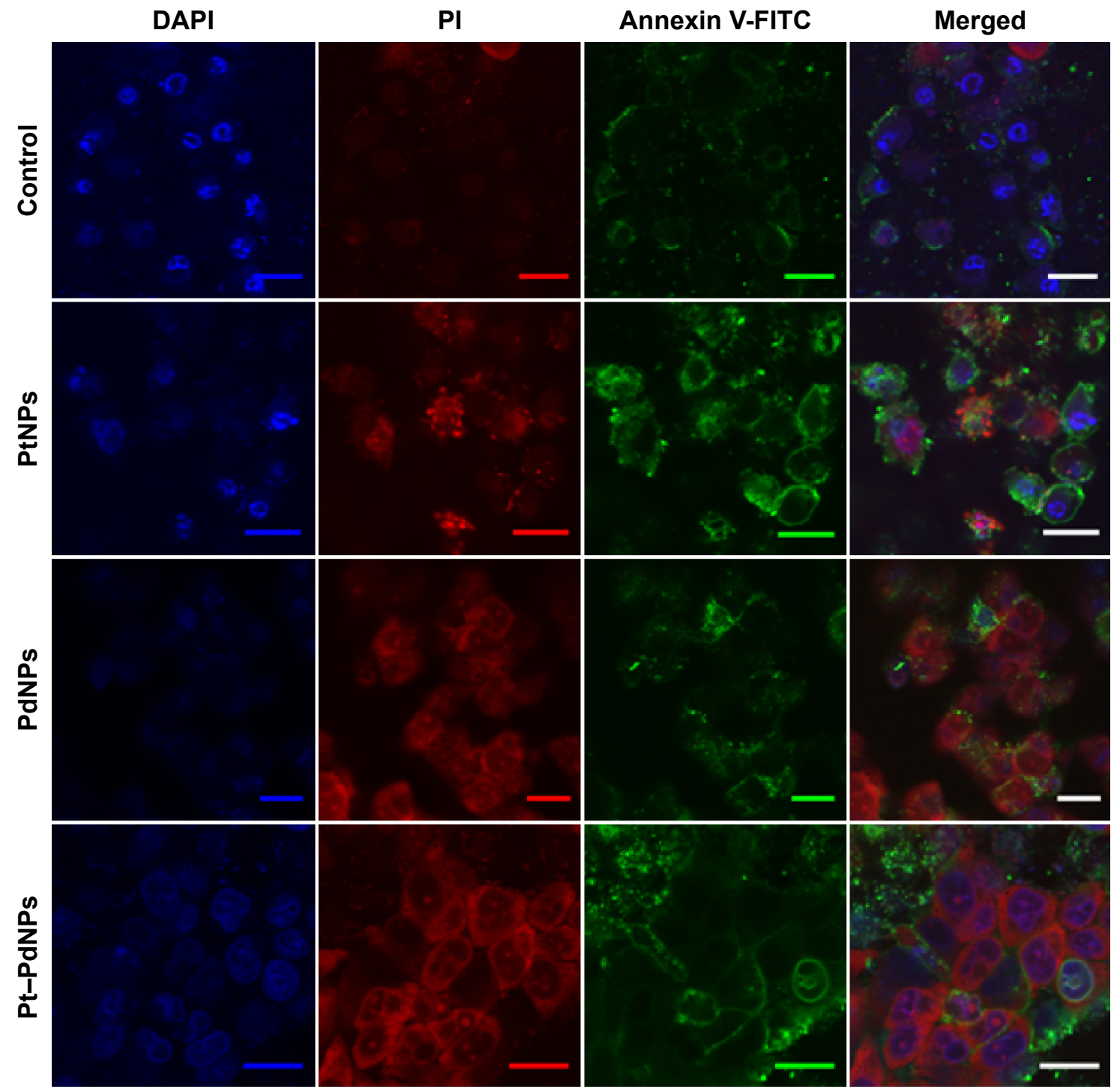

Figure 7 Apoptosis: HeLa cells seeded on coverslips were treated with $10 \mu \mathrm{g} \mathrm{mL} \mathrm{L}^{-1}$ of PtNPs, PdNPs, and Pt-PdNPs for 48 hours, and then stained for Annexin V-FITC and PI. Note: Inset represents scale bar equivalent to $20 \mu \mathrm{m}$.

Abbreviations: PdNPs, palladium nanoparticles; PI, propidium iodide; PtNPs, platinum nanoparticles; Pt-PdNPs, platinum-palladium bimetallic nanoparticles; DAPI, 4',6diamidino-2-phenylindole; FITC, fluorescein isothiocyanate. 


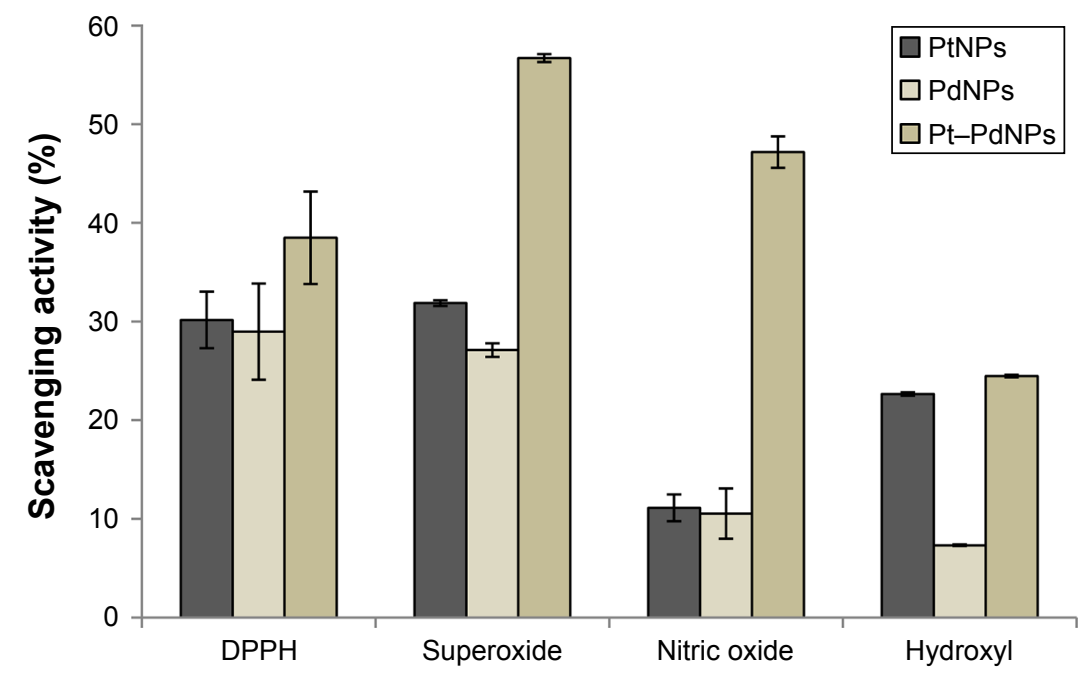

Figure 8 Antioxidant activities of PtNPs, PdNPs, and Pt-PdNPs synthesized by DBTE.

Abbreviations: DBTE, Dioscorea bulbifera tuber extract; DPPH, 2,2-diphenyl-I-picrylhydrazyl; PdNPs, palladium nanoparticles; PtNPs, platinum nanoparticles; Pt-PdNPs, platinum-palladium bimetallic nanoparticles.

to be slower as compared to the gold nanoparticles by D. bulbifera as reported earlier. This relatively low rate of bioreduction could be attributed due to the probable difficulty in initial formation of Pt nuclei. This could be reflected in the fact that $100 \%$ conversion of PtNPs by DBTE required longer time and higher temperature than gold nanoparticles. ${ }^{35}$ PtNPs synthesized by DBTE were found to be very small $(<5 \mathrm{~nm})$ uniform and monodispersed unlike the bigger mixed aggregation (2-20 nm) comprised of mixture of spheres and plates as obtained during synthesis by Diospyros kaki leaf extract. $^{35}$

A similar high temperature and time as that of PtNPs was required for complete synthesis of PdNPs, as well. However, synthesis of PdNPs by DBTE was faster as compared to the recent report on synthesis of PdNPs by Gardenia jasminoides Ellis, which took 24 hours for complete reduction at $60^{\circ} \mathrm{C} . .^{36}$ Blunt ended $\mathrm{Pd}$ nanocubes or nanospheres in a range between 10 and $20 \mathrm{~nm}$ were found to be uniformly dispersed without showing any agglomeration. Similarly, results in case of $G$. jasminoides Ellis was concluded to be attributed due to natural stabilizers present in the crude aqueous extract and elevated temperature. Thus, the phytochemical mixtures of reducing and stabilizing agents in DBTE might be playing a predominant role in the particle assembly. Under excitation at higher temperature, availability of abundant Pd crystal nuclei facilitated the formation of tiny spherical particles, which further grew rapidly by consumption of Pd ions without any external addition of either reducing or stabilizing agents. ${ }^{36}$ However, to the best of our knowledge there are no reports of bimetallic Pt-PdNPs from medicinal plant $D$. bulbifera. Thus, the reported synthesis ensured a unique irregular flower like architecture with synergistic enhancement of bioactivity. Chemically synthesized similar heterogeneous bimetallic nanostructures, reported recently, were expected to integrate diverse functionalities in a single crystal structure. ${ }^{37}$

Bioreduced PtNPs showed anticancer activity against HeLa cells. Pt complexes are well known anticancer agents and drugs like cisplatin, carboplatin, and oxaliplatin, in addition to nedaplatin, lobaplatin, and heptaplatin. ${ }^{38}$ In case of individual PtNPs, the activity was found to be low. However, the anticancer efficacy was considerably enhanced synergistically in Pt-PdNPs. It is well documented that Pt complexes shows a pronounced variability in triggering the death in cancer cells. The underlying mechanism of action plays a key role in this selectivity, which is reflected in case of the drugs like cisplatin that kills certain cancer cells but not others. Similarly, other Pt complexes fail to exhibit same levels of cytotoxicity to the cancer cells that are highly sensitive to cisplatin. Such variability was best explained by two possible reasons: 1) the physicochemical properties of nanoparticles that derive from their structure and 2) the array of metabolic events like gene expression, protein synthesis, post-translational modification, and synthesis of small molecules, in the cell in response to the exposure to PtNPs, PdNPs, and Pt-PdNPs. ${ }^{38}$ Enhancement of activity in Pt-PdNPs as compared to individual PtNPs reflects that combination with transition metal like Pd can synergistically increase anticancer activity. Our results are in close agreement to earlier reports, where it is documented that although drugs like satraplatin, miriplatin, prolindac, aroplatin, and picoplatin are in developmental stages, the 
side effects ranging from nephrotoxicity to drug resistance of the tumor cells have posed real challenges to researchers, which have prompted to consider the combination of transition metals with biologically active molecules as a successful strategy toward designing promising anticancer agents. ${ }^{39}$ Flow cytometric analysis confirming maximum dual positive cells $\left(\mathrm{AV}-\mathrm{FITC}^{+} \mathrm{PI}^{+}\right)$in $\mathrm{Pd}-\mathrm{PtNPs}$ treated HeLa cells indicated the efficient and synergistic induction of apoptosis by both $\mathrm{Pt}$ and $\mathrm{Pd}$ components in Pt-PdNPs. FITC-AV binding is highly specific to early stages of apoptosis, which is marked by transposition of phosphatidylserine from the internal to the outer surface of cell membrane. ${ }^{19,40} \mathrm{Pt}-\mathrm{PdNPs}$ exhibited superior triggered translocation of phosphatidylserine as compared to individual PtNPs and PdNPs indicating extensive damage to cell membrane leading to apoptotic effects rather than necrosis. Antioxidants are considered to be one of the most promising cancer chemopreventive agent that can reverse, suppress, or prevent carcinogenic progression. Reactive oxygen species production is found to be extensive in tumor cells, which upregulates certain growth factors and matrix metalloproteinases, promoting angiogenesis, metastasis, and secondary tumor developments. ${ }^{41}$ In our study we found that the nanoparticles were not only cytotoxic against the cancer cells, but also possess antioxidant properties. It was evident that the free radical scavenging potential increased in the bimetallic nanoparticles (Pt-PdNPs) as compared to individual NPs. Our results are strongly in agreement with a recent report, which has demonstrated that a mixture of $\mathrm{Pd}$ and Pt nanoparticles, used in Japan since last 60 years or more for treating chronic diseases, possess remarkable superoxide dismutase and catalase activity in in vivo mice model and thereby, considered as a powerful tool to control age related skin disease caused by oxidative damage. ${ }^{42}$ Another such study provides a strong scientific rationale to the fact that PtNPs are superoxide dismutase/catalase mimetic, thus have significant antiaging properties by increasing the lifespan in Caenorhabditis elegans. ${ }^{43}$ In view of the background, consideration of $\mathrm{Pt}$ as a component can serve as a pivotal strategy to design and explore combinatorial effect of bimetallic nanomaterials.

\section{Conclusion}

This is the first report on rapid and efficient synthesis of novel PtNPs, PdNPs, and Pt-PdNPs using traditional medicinal plant $D$. bulbifera within 5 hours. The particles were found to be almost monodispersed in the size range of $2-25 \mathrm{~nm}$ and stable. A synergistic activity enhancement was evident in the bimetallic Pt-PdNPs as compared to individual PtNPs or PdNPs. The particles exhibited potent anticancer and antioxidant activity. Hereby, it is of utmost scientific rationale to design and explore the combined effects of Pt-PdNPs as novel biomedicine. It can serve dual purpose of preventing cancer progression by its antioxidant properties as well as induction of apoptosis and cell death by its cytotoxic potential against cancer cells.

\section{Acknowledgment}

The authors acknowledge the help extended for the use of TEM and HRTEM facilities in Chemical Engineering and CRNTS funded by the DST through Nanomission and IRPHA schemes and Board of College and University Development (BCUD), Savitribai Phule Pune University for research grant (11SCI001810). S Ghosh thanks Council of Scientific and Industrial Research (CSIR, Government of India) for Senior Research Fellowship (09/137(0516)/2012EMR-I). Dr Geetanjali Tomar thanks DST INSPIRE for the faculty position and the research grant (IFA13 LSBM73 and GOI-E-161(2), respectively).

\section{Disclosure}

The authors report no conflicts of interest in this work.

\section{References}

1. Sohn EK, Johari SA, Kim TG, et al. Aquatic toxicity comparison of silver nanoparticles and silver nanowires. BioMed Res Int. 2015;2015: 893049.

2. Salunke GR, Ghosh S, Santosh Kumar RJ, et al. Rapid efficient synthesis and characterization of silver, gold, and bimetallic nanoparticles from the medicinal plant Plumbago zeylanica and their application in biofilm control. Int J Nanomed. 2014;9:2635-2653.

3. Gaidhani SV, Yeshvekar RK, Shedbalkar UU, Bellare JH, Chopade BA. Bio-reduction of hexachloroplatinic acid to platinum nanoparticles employing Acinetobacter calcoaceticus. Process Biochem. 2014;49(12): 2313-2319.

4. Shedbalkar U, Singh R, Wadhwani S, Gaidhani S, Chopade BA. Microbial synthesis of gold nanoparticles: current status and future prospects. Adv Colloid Interface Sci. 2014;209:40-48.

5. Singh R, Nawale LU, Arkile M, et al. Chemical and biological metal nanoparticles as antimycobacterial agents: a comparative study. Int J Antimicrob Agents. 2015;46(2):183-188.

6. Wadhwani SA, Shedbalkar UU, Singh R, Karve MS, Chopade BA. Novel polyhedral gold nanoparticles: green synthesis, optimization and characterization by environmental isolate of Acinetobacter sp. SW30. World J Microb Biotechnol. 2014;30(10):2723-2731.

7. Sant DG, Gujarathi TR, Harne SR, et al. Adiantum philippense L. frond assisted rapid green synthesis of gold and silver nanoparticles. J Nanopart. 2013;2013:1-9.

8. Gaidhani S, Singh R, Singh D, et al. Biofilm disruption activity of silver nanoparticles synthesized by Acinetobacter calcoaceticus PUCM 1005. Mater Lett. 2013;108:324-327.

9. Singh R, Wagh P, Wadhwani S, et al. Synthesis, optimization, and characterization of silver nanoparticles from Acinetobacter calcoaceticus and their enhanced antibacterial activity when combined with antibiotics. Int J Nanomed. 2013;8:4277-4290. 
10. Long NV, Chien ND, Hayakawa T, Hirata H, Lakshminarayana G, Nogami M. The synthesis and characterization of platinum nanoparticles: a method of controlling the size and morphology. Nanotechnology. 2010;21(3):035605.

11. Susut C, Nguyen TD, Chapman GB, Tong Y. Shape and size stability of Pt nanoparticles for $\mathrm{MeOH}$ electro-oxidation. Electrochim Acta. 2008; 53(21):6135-6142.

12. Han SB, Song YJ, Lee JM, Kim JY, Park KW. Platinum nanocube catalysts for methanol and ethanol electrooxidation. Electrochem Commun 2008;10(7):1044-1047.

13. Kim C, Lee H. Shape effect of Pt nanocrystals on electrocatalytic hydrogenation. Catal Commun. 2009;11(1):7-10.

14. Chen J, Lim B, Lee EP, Xia Y. Shape-controlled synthesis of platinum nanocrystals for catalytic and electrocatalytic applications. Nano Today. 2009;4(1):81-95.

15. Cutillas N, Yellol GS, De Haro C, Vicente C, Rodríguez V, Ruiz J. Anticancer cyclometalated complexes of platinum group metals and gold. Coord Chem Rev. 2013;257(19-20):2784-2797.

16. Sawoo S, Srimani D, Dutta P, Lahiri R, Sarkar A. Size controlled synthesis of $\mathrm{Pd}$ nanoparticles in water and their catalytic application in C-C coupling reactions. Tetrahedron. 2009;65(22):4367-4374.

17. Ho PF, Chi KM. Size-controlled synthesis of Pd nanoparticles from $\beta$-diketonato complexes of palladium. Nanotechnology. 2004;15(8): 1059-1064.

18. Petrarca C, Clemente E, Giampaolo LD, et al. Palladium nanoparticles induce disturbances in cell cycle entry and progression of peripheral blood mononuclear cells: paramount role of ions. J Immunol Res. 2014; Article ID 295092, 8 pages.

19. Ghosh S, More P, Derle A, et al. Diosgenin functionalized iron oxide nanoparticles as novel nanomaterial against breast cancer. $J$ Nanosci Nanotechnol. 2015;15:9464-9472.

20. Ghosh S, Patil S, Ahire M, et al. Gnidia glauca flower extract mediated synthesis of gold nanoparticles and evaluation of its chemocatalytic potential. J Nanobiotechnol. 2012;10:17.

21. Kitture R, Ghosh S, More PA, et al. Curcumin-loaded, self-assembled Aloe vera template for superior antioxidant activity and trans-membrane drug release. J Nanosci Nanotechnol. 2015;15(6):4039-4045.

22. Kitture R, Chordiya K, Gaware S, et al. ZnO nanoparticles-red sandalwood conjugate: a promising anti-diabetic agent. J Nanosci Nanotechnol. 2015;15(6):4046-4051.

23. Kitture R, Ghosh S, Kulkarni P, et al. $\mathrm{Fe}_{3} \mathrm{O}_{4}$-citrate-curcumin: promising conjugates for superoxide scavenging, tumor suppression and cancer hyperthermia. J Appl Phys. 2012;111:064702-064707.

24. Ghosh S, Derle A, Ahire M, et al. Phytochemical analysis and free radical scavenging activity of medicinal plants Gnidia glauca and Dioscorea bulbifera. PLoS One. 2013;8(12):e82529.

25. Ghosh S, More P, Derle A, et al. Diosgenin from Dioscorea bulbifera: novel hit for treatment of Type II diabetes mellitus with inhibitory activity against $\alpha$-amylase and $\alpha$-glucosidase. PLoS One. 2014;9(9): e106039.

26. Ghosh S, Ahire M, Patil S, et al. Antidiabetic activity of Gnidia glauca and Dioscorea bulbifera: potent amylase and glucosidase inhibitors. Evid Based Complement Alternat Med. 2012;2012:929051.
27. Ghosh S, Parihar VS, More P, Dhavale DD, Chopade BA. Phytochemistry and therapeutic potential of medicinal plant: Dioscorea bulbifera. Med Chem. 2015;5(4):154-159.

28. Ghosh S, Jagtap S, More P, et al. Dioscorea bulbifera mediated synthesis of novel $\mathrm{Au}_{\text {core }} \mathrm{Ag}_{\text {shell }}$ nanoparticles with potent antibiofilm and antileishmanial activity. J Nanomater. 2015;2015:562938.

29. Ghosh S, Patil S, Ahire M, et al. Synthesis of silver nanoparticles using Dioscorea bulbifera tuber extract and evaluation of its synergistic potential in combination with antimicrobial agents. Int J Nanomed. 2012;7: 483-496.

30. Ghosh S, Patil S, Ahire M, et al. Synthesis of gold nanoanisotrops using Dioscorea bulbifera tuber extract. J Nanomater. 2011;2011:354793.

31. Shafii S, Lihua W, Nordin MR, Yong LK. Synthesis of palladiumplatinum bimetallic nanoparticles and their catalytic activity towards the hydrogenation reaction of palm olein. J Chem Eng Process Technol. 2012;3:1.

32. Adersh A, Ghosh S, More P, Chopade BA, Gandhi MN, Kulkarni AR Surface defect rich $\mathrm{ZnO}$ quantum dots as antioxidant inhibiting $\alpha$-amylase and $\alpha$-glucosidase: a potential anti-diabetic nanomedicine. J Mater Chem B. 2015;3(22):4597-4606.

33. Patil AB, Ghosh S, Phadatare SD, et al. Evaluation of malonic acid diamide analogues as radical scavenging agents. NJ Chem. 2015;39:1267-1273.

34. Soundarrajan C, Sankari A, Dhandapani P, et al. Rapid biological synthesis of platinum nanoparticles using Ocimum sanctum for water electrolysis applications. Bioprocess Biosyst Eng. 2012;35(5):827-833.

35. Song JY, Kwon EY, Kim BS. Biological synthesis of platinum nanoparticles using Diopyros kaki leaf extract. Bioprocess Biosyst Eng. 2010; 33(1):159-164.

36. Jia L, Zhang Q, Li Q, Song H. The biosynthesis of palladium nanoparticles by antioxidants in Gardenia jasminoides Ellis: long lifetime nanocatalysts for p-nitrotoluene hydrogenation. Nanotechnology. 2009; 20(38):385601.

37. Peng Z, Yang H. Synthesis and oxygen reduction electrocatalytic property of Pt-on-Pd bimetallic heteronanostructures. J Am Chem Soc. 2009;131(22):7542-7543.

38. Wexselblatt E, Yavin E, Gibson D. Cellular interactions of platinum drugs. Inorganica Chim Acta. 2012;393:75-83.

39. Kapdi R, Fairlamb IJS. Anti-cancer palladium complexes: a focus on PdX2L2, palladacycles and related complexes. Chem Soc Rev. 2014; 43(13):4751-4777.

40. Mallick A, More P, Ghosh S, et al. Dual drug conjugated nanoparticle for simultaneous targeting of mitochondria and nucleus in cancer cells. ACS Appl Mater Interfaces. 2015;7(14):7584-7598.

41. Rajkumar V, Guha G, Kumar RA. Antioxidant and anti-cancer potentials of Rheum emodi rhizome extracts. Evid Based Complement Alternat Med. 2011;2011:697986.

42. Shibuya S, Ozawa Y, Watanabe K, et al. Palladium and platinum nanoparticles attenuate aging-like skin atrophy via antioxidant activity in mice. PLoS One. 2014;9(10):e109288.

43. Kim J, Takahashi M, Shimizu T, et al. Effects of a potent antioxidant, platinum nanoparticle, on the lifespan of Caenorhabditis elegans. Mech Ageing Dev. 2008;129(6):322-331. 


\section{Supplementary materials}

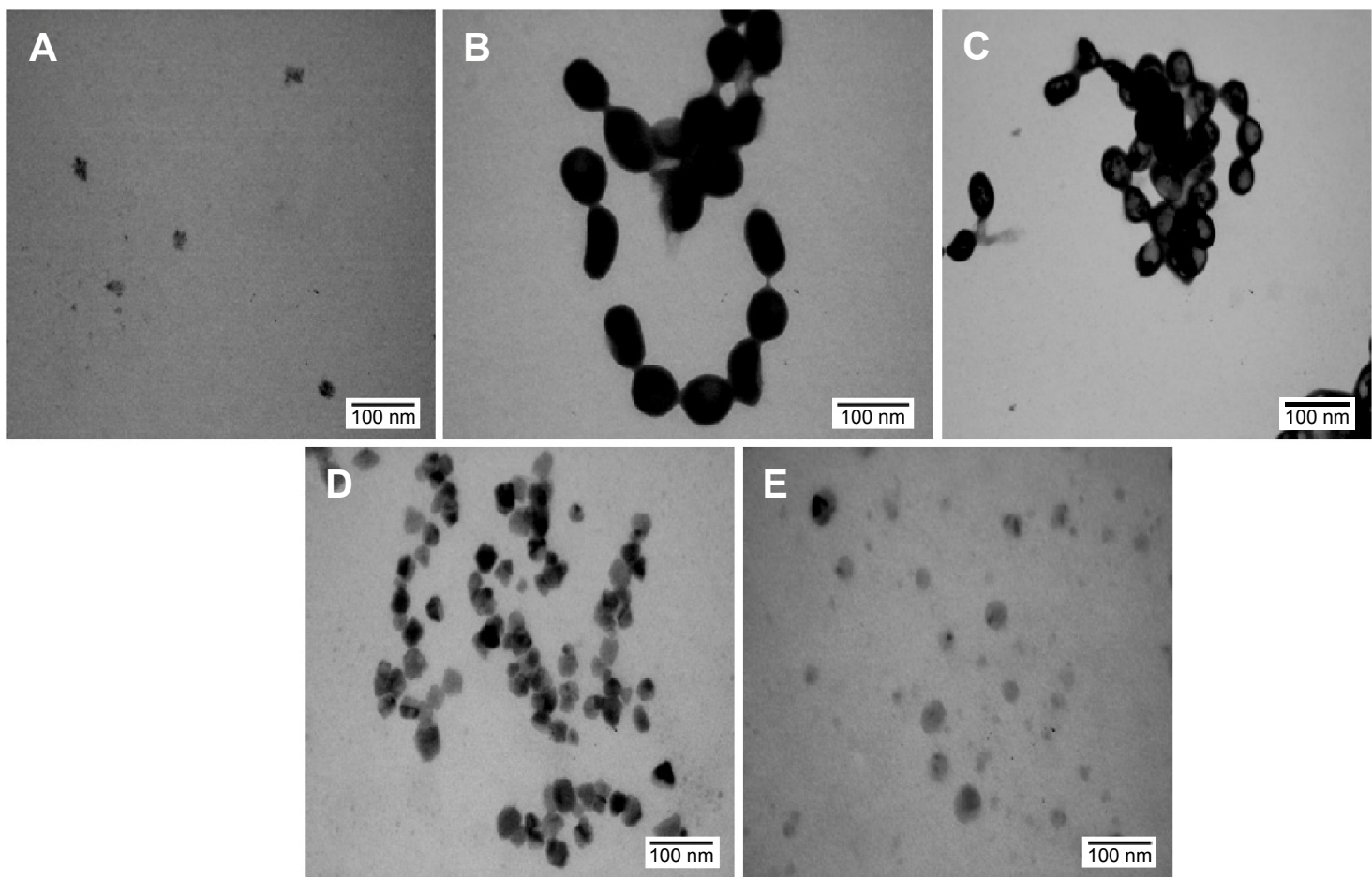

Figure SI Characterization by TEM.

Notes: (A) Chemically synthesized PtNPs; (B) chemically synthesized PdNPs; (C) chemically synthesized Pt-PdNPs; (D) DBTE synthesized Pt-PdNPs using I:2 molar ratio of platinum and palladium salt; (E) DBTE synthesized Pt-PdNPs using 2:I molar ratio of platinum and palladium salt.

Abbreviations: DBTE, Dioscorea bulbifera tuber extract; PdNPs, palladium nanoparticles; PtNPs, platinum nanoparticles; Pt-PdNPs, platinum-palladium bimetallic nanoparticles; TEM, transmission electron microscope.
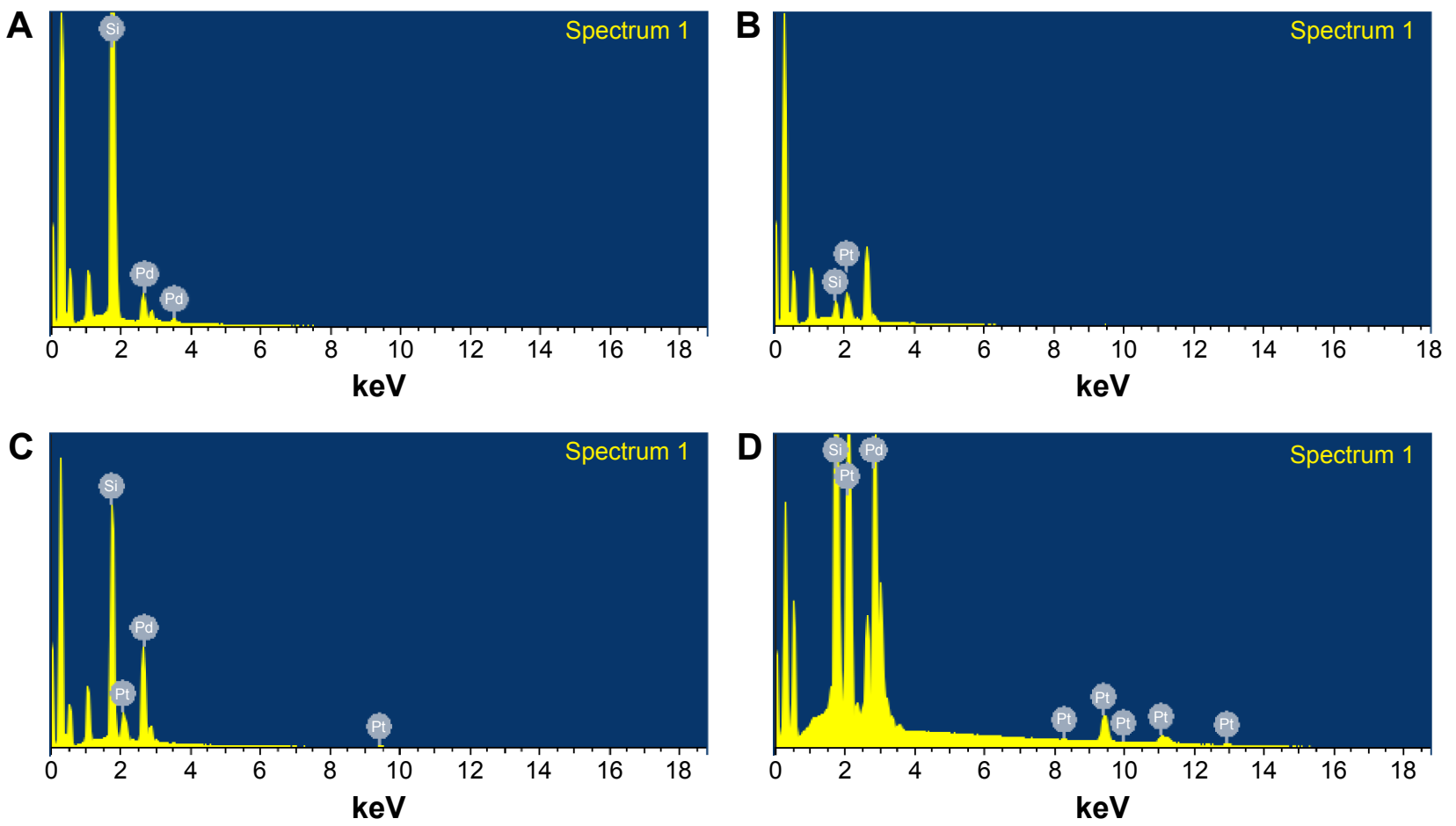

Figure $\mathbf{S 2}$ (Continued) 


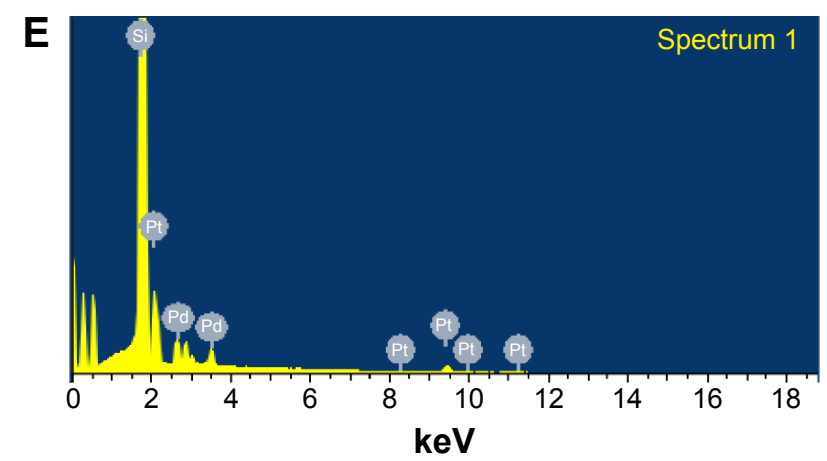

Figure S2 Energy dispersive spectroscopy analysis.

Notes: (A) Representative spot EDS profile of chemically synthesized PtNPs showing $87.32 \%$ elemental platinum. (B) Representative spot EDS profile of chemically synthesized PdNPs showing 7.25\% elemental palladium. (C) Representative spot EDS profile of chemically synthesized Pt-PdNPs showing $31.59 \%$ elemental platinum and $21.49 \%$ elemental palladium. (D) Representative spot EDS profile of DBTE synthesized Pt-PdNPs using I:2 molar ratio of platinum and palladium salt, respectively showing $36.29 \%$ elemental platinum and $41.20 \%$ elemental palladium. (E) Representative spot EDS profile of DBTE synthesized Pt-PdNPs using 2:I molar ratio of platinum and palladium salt, respectively showing $14.5 \%$ elemental platinum and $4.16 \%$ elemental palladium.

Abbreviations: DBTE, Dioscorea bulbifera tuber extract; EDS, energy dispersive spectroscopy; PdNPs, palladium nanoparticles; PtNPs, platinum nanoparticles; Pt-PdNPs, platinum-palladium bimetallic nanoparticles.

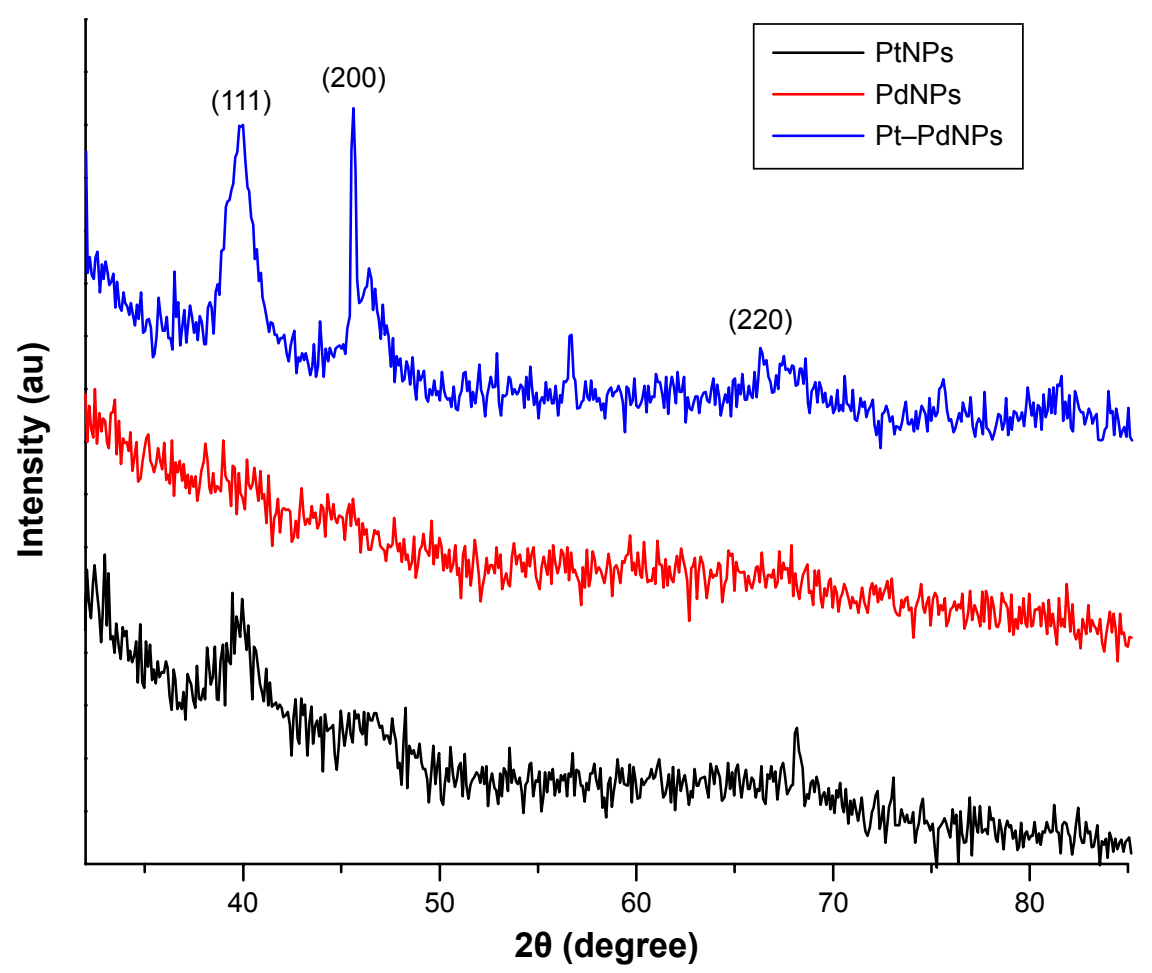

Figure S3 Representative X-ray diffraction profile of thin film PtNPs, PdNPs, and Pt-PdNPs synthesized by DBTE.

Abbreviations: au, arbitrary unit; PdNPs, palladium nanoparticles; PtNPs, platinum nanoparticles; Pt-PdNPs, platinum-palladium bimetallic nanoparticles; DBTE, Dioscorea bulbifera tuber extract. 


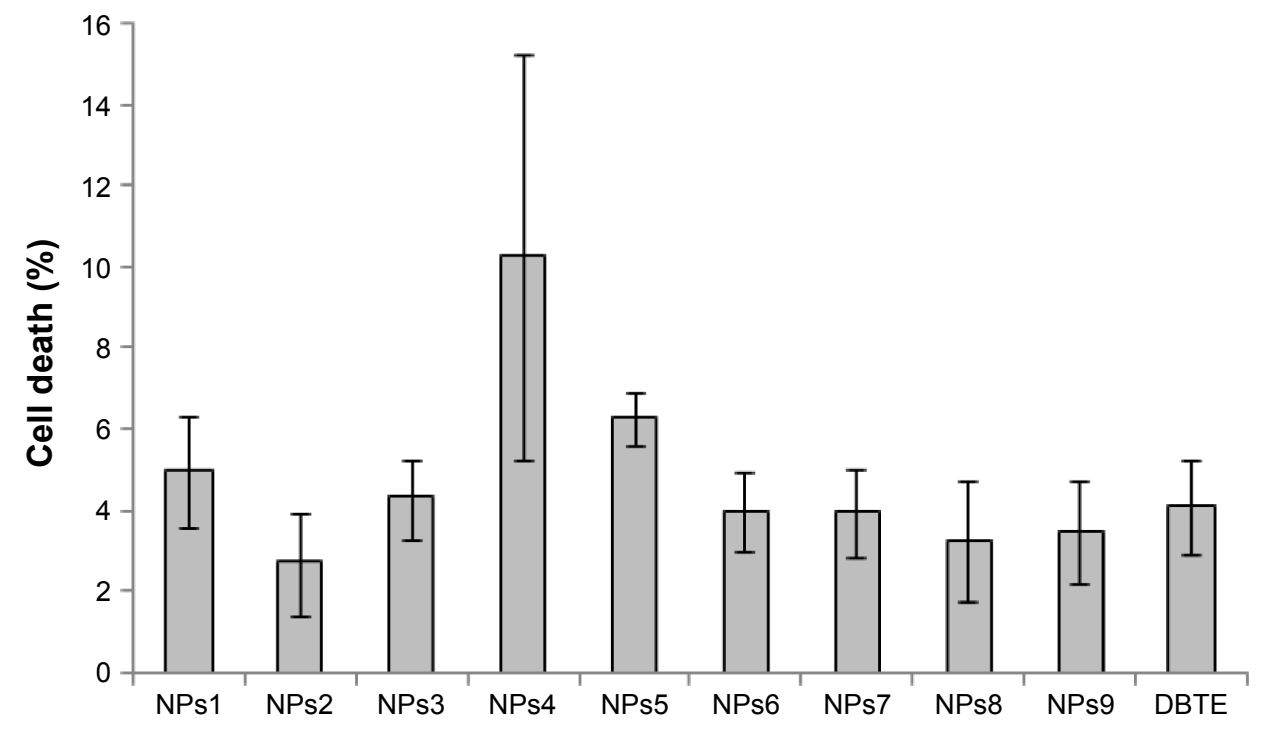

Figure S4 Antiproliferative activity against HeLa cells.

Notes: Comparative activities of chemically synthesized PtNPs (NPs I), chemically synthesized PdNPs (NPs2), chemically synthesized Pt-PdNPs (NPs3), DBTE + chemically synthesized PtNPs (NPs4), DBTE + chemically synthesized PdNPs (NPs5), DBTE + chemically synthesized Pt-PdNPs (NPs6), DBTE synthesized Pt-PdNPs using I:2 molar ratio of platinum and palladium salt (NPs7), DBTE synthesized Pt-PdNPs using 2:I molar ratio of platinum and palladium salt (NPs8), physical mixture of PtNPs and PdNPs (NPs9), and only DBTE.

Abbreviations: DBTE, Dioscorea bulbifera tuber extract; PdNPs, palladium nanoparticles; PtNPs, platinum nanoparticles; Pt-PdNPs, platinum-palladium bimetallic nanoparticles.

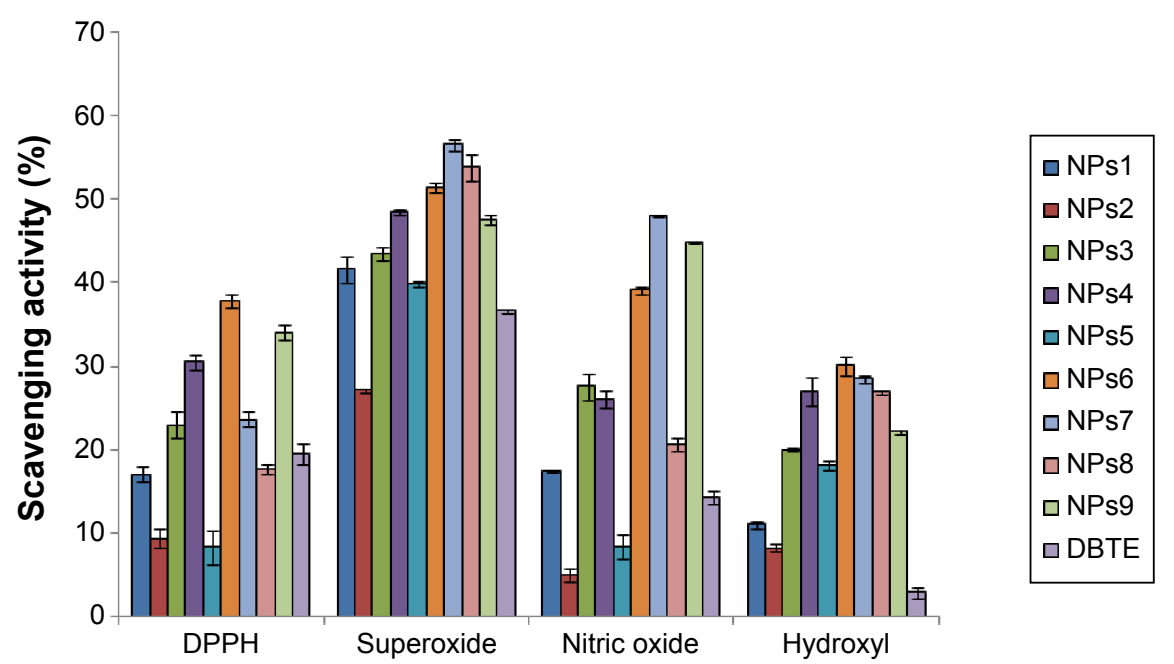

Figure S5 Comparative antioxidant activities of chemically synthesized PtNPs (NPsI), chemically synthesized PdNPs (NPs2), chemically synthesized Pt-PdNPs (NPs3), DBTE + chemically synthesized PtNPs (NPs4), DBTE + chemically synthesized PdNPs (NPs5), DBTE + chemically synthesized Pt-PdNPs (NPs6), DBTE synthesized Pt-PdNPs using 1:2 molar ratio of platinum and palladium salt (NPs7), DBTE synthesized Pt-PdNPs using 2:I molar ratio of platinum and palladium salt (NPs8), physical mixture of PtNPs and PdNPs (NPs9), and only DBTE.

Abbreviations: DBTE, Dioscorea bulbifera tuber extract; PdNPs, palladium nanoparticles; PtNPs, platinum nanoparticles; Pt-PdNPs, platinum-palladium bimetallic nanoparticles; DPPH, 2,2-diphenyl-I-picrylhydrazyl.

\section{Dovepress}

\section{Publish your work in this journal}

The International Journal of Nanomedicine is an international, peerreviewed journal focusing on the application of nanotechnology in diagnostics, therapeutics, and drug delivery systems throughout the biomedical field. This journal is indexed on PubMed Central, MedLine, CAS, SciSearch $®$, Current Contents ${ }^{\circledR} /$ Clinical Medicine,
Journal Citation Reports/Science Edition, EMBase, Scopus and the Elsevier Bibliographic databases. The manuscript management system is completely online and includes a very quick and fair peer-review system, which is all easy to use. Visit http://www.dovepress.com/ testimonials.php to read real quotes from published authors. 